\title{
FIQUE EM CASA! E QUANDO A CASA NÃO É UM ESPAÇO SEGURO? REFLEXÕES SOBRE O AUMENTO DA VIOLÊNCIA CONTRA MULHER EM TEMPOS DE PANDEMIA COVID-19
}

\author{
STAY AT HOME! AND WHEN IS THE HOUSE NOT A SAFE SPACE? REFLECTIONS ON \\ INCREASING VIOLENCE AGAINST WOMEN IN PANDEMIC COVID-19
}

DOI: http://dx.doi.org/10.16891/2317-434X.v8.e3.a2020.pp793-797

Recebido em: 20.08.2020 | Aceito em: 26.10.2020

\author{
Kariciane Santos Teles ${ }^{*}$, Indira Feitosa Siebra de Holanda ${ }^{a}$
}

Centro Universitário Doutor Leão Sampaio - UNILEÃOa

*E-mail: kariciateles@hotmail.com

\section{RESUMO}

O presente estudo mostra que apesar das mulheres terem lutado e conseguido alguns direitos na sociedade, estas ainda continuam lutando pelo direito a vida. Estudos mostram que houve aumento da violência contra mulher durante o período de isolamento social ocasionado pelo Covid-19. Nesse sentido, se percebe que a violência de gênero trata-se de um fenômeno complexo que precisa de mais atenção das diversas áreas do conhecimento como a psicologia, Direito, entre outras. Dessa forma, esse estudo tem por objetivo analisar o aumento da violência contra mulher em tempos de pandemia e com isso investigar como o isolamento social tem contribuído para a elevação desse tipo de violência, assim como apresentar o aumento das notificações da violência contra mulher em tempos de pandemia. Como método de pesquisa foi utilizado levantamento bibliográfica sendo a pesquisa com abordagem qualitativa e de natureza descritiva e exploratória. Foi percebido durante essa pesquisa que teve um aumento significativo nas solicitações de medidas protetivas ocasionadas pelo isolamento social bem como o aumento de feminicídios.

Palavras-chave: Isolamento Social; Violência Doméstica; Proteção.

\section{ABSTRACT}

The present study shows that although women have fought and achieved some rights in society, they are still fighting for the right to life. Studies show that there was an increase in violence against women during the period of social isolation caused by Covid-19. In this sense, it is noticed that gender violence is a complex phenomenon that needs more attention from different areas of knowledge such as psychology, law, among others. Thus, this study aims to analyze the increase in violence against women in times of pandemic and thereby investigate how social isolation has contributed to the increase in this type of violence, as well as presenting the increase in notifications of violence against women in times pandemic. As a research method, a bibliographic survey was used, being the research with a qualitative approach and of a descriptive and exploratory nature. It was noticed during this research that there was a significant increase in requests for protective measures caused by social isolation as well as an increase in femicides.

Keyword: Social Isolation; Domestic violence; Protection. 


\section{INTRODUÇÃO}

A violência contra mulher pode ser definida como toda e qualquer ação baseada no gênero que resulte em lesões físicas, sexuais ou psicológicas e que venha trazer danos a integridade física e emocional desse sujeito (MACHADO, 2020). O presente estudo consiste em uma pesquisa bibliográfica e documental de caráter quantiquali. A pesquisa apresenta relevância na medida em que orienta a população sobre quais os tipos de ferramentas podem ser utilizadas para proteção dessas vitimas, por essa razão a autora do projeto em questão e futura psicóloga acredita na validade desse construto como uma forma de contribuir e levar o conhecimento a população a cerca da violência contra as mulheres.

\section{FUNDAMENTAÇÃO TEÓRICA}

Por muito tempo a mulher procurou conquistar seu espaço na sociedade e até chegar aos dias de hoje, foram muitas lutas e conquistas, como, por exemplo, ter direito a voto, igualdade salarial, controle do seu corpo e da fertilidade. Antes, a mulher era vista apenas como um ser reprodutor, essas transformações ocorreram após o movimento feminista na segunda década do ano de 1960. Apesar desses avanços, se percebe que há na sociedade uma desigualdade de gênero, compreendem-se como gênero a distinção de características entre os sujeitos, por exemplo, Homem $\mathrm{X}$ Mulher. Por meio dessa classificação é possível atribuir significados socioculturais que reforçam essas divergências anatômicas, devido a essas diferenças as mulheres são consideradas submissas aos homens, isso é possível devido à discriminação de gênero que torna essas mulheres, vítimas de diversos tipos de violência, dentre elas evidencia a violência física, psicológica e sexual. Isso ocorre por que na sociedade existem aspectos culturais e históricos que reforçam o patriarcado.

Portanto a violência contra mulher se reproduz nas relações de poder em que a mesma se encontra, vivemos em uma sociedade machista e patriarcal que possibilita ao homem o direito de dominar e controlar suas vitimas e que muitas vezes utiliza-se desse poder para violenta-las. Por isso acredita-se que o patriarcado é considerado um fator preponderante para o desencadeamento da violência.

A violência pode se apresentar de diversas formas o que possibilita dizer que é considerada um fenômeno multicausal. Concomitante a esse pensamento apresenta-se os três tipos de violência mais recorrente na sociedade (ARJONA, 2019).

\section{TIPOS DE VIOLÊNCIA:}

\section{-Violência Física}

Trata-se de toda e qualquer ação que venha a machucar a integridade do sujeito, geralmente ocorre quando uma pessoa se sobrepõe a outra na relação, estabelecendo relações de poder. Violência física: chutes, socos, mordida e empurrão, arremesso de objetos contra a mulher, socos, pontapés entre outros, podendo chegar a assassinatos (BRASIL, 2006).

\section{- Violência Psicológica}

Algumas vezes esse tipo de violência é confundido como ciúmes, ou forma de cuidado que o opressor tem com a vítima, boa parte das mulheres não sabem que isso é um tipo de agressão a sua saúde mental e pode ocorrer de forma gradual, fazendo com que a vítima não perceba (BRASIL, 2006).

\section{- Violência Sexual}

Trata-se de atos ou tentativa sexual sem permissão da vítima, seja ela forçada ou por coação, esse tipo de violência pode ocorrer tanto na relação conjugal como nos demais tipos de relacionamento, ocorre geralmente no espaço doméstico, o que o torna invisível, essa agressão pode acontecer em qualquer tipo de relação, cultura e até mesmo em diferentes classes (BRASIL, 2006).

\section{- Violência Moral e Patrimonial}

Compreende-se por violência moral toda ação que tem o objetivo de denigrir a integridade física do sujeito como calunia difamação. Quando se trata da violência patrimonial é quando o agressor interfere diretamente nos bens da vitima, por exemplo, controle de dinheiro, furto, ou ate mesmo a omissão de pagamento de pensões.

\section{METODOLOGIA}

Para a realização deste trabalho de revisão de literatura a busca dos artigos e trabalhos foi realizada no período de 22 de Junho a 08 de julho de 2020, consultados nos bancos de dados eletrônicos: Periódicos Eletrônicos de Psicologia (PePSIC), Biblioteca Eletrônica Científica Online (SciElo) e dados do Ministério da Saúde, assim como sites de Jornais conhecidos, utilizando os descritores: "violência contra a mulher", "violência domestica". 
Foram realizadas buscas avançadas nas bases de dados eletrônicas citadas acima utilizando os filtros de pesquisas como campo específico de busca de título, resumo e texto completo, ano de publicação $2020 \mathrm{com}$ as seguintes combinações de descritores: (ti(violência domestica)) ou (ti(violência AND mulher)).

Os critérios de inclusão utilizados para compor este trabalho incluem artigos que abordem sobre a violência contra a mulher pré-pandemia e pós-pandemia da COVID-19 no Brasil, além de trabalhos contendo dados estatísticos referentes aos índices de violência contra a mulher. Foram utilizados como critérios de exclusão aqueles trabalhos que não abordassem sobre violência domestica contra a mulher ou que tratasse de outros tipos de violência que não fosse a domestica.

Os estudos inclusos nesse trabalho são de natureza quantitativa e qualitativa, com o intuito de obter dados estatísticos para o embasamento da pesquisa, sendo está caracterizada como descritiva e exploratória.

\section{RESULTADO E DISCUSSÃO}

Em 2020 o mundo foi surpreendido com o surgimento de uma grande pandemia, oriunda do (SARSCoV-2) ou como é conhecida popularmente como COVID-19 nome dado a uma síndrome respiratória Grave que afeta todo o organismo podendo levar a pessoa infectada ao óbito. Segundo a Organização Mundial de Saúde (OMS) define a pandemia como a disseminação de uma doença cuja propagação é muito rápida podendo assim se espalhar por diversos continentes e por uma transmissão sustentada entre pessoas.

Devido ao aumento e propagação muito veloz dos casos de COVID-19 a (OMS) recomendou algumas medidas de prevenção para auxiliar no combate a disseminação do vírus entre estas medidas estão ações de higiene e distanciamento social. $\mathrm{O}$ isolamento social contribuiu consideravelmente para a elevação da violência contra mulher nesse período de pandemia. Segundo o site O GLOBO, 2020 a elevação de casos foi de $50 \%$ apenas na cidade do Rio de Janeiro, porém, destaca que esses índices podem aumentar, pois, boa parte das mulheres não denuncia seus agressores muitas vezes com medo das consequências dessa denuncia, ou simplesmente pelo sentimento de culpa que pode emergir nessas mulheres, importante destacar que as vitimas desses tipos de violência em epigrafe muitas vezes não sabem que sofrem de violência tendo dificuldade de identificar que está inserida em uma relação abusiva.

A cidade de São Paulo também teve aumento dos casos $30 \%$ de acordo com o portal de noticias da Globo, 2020 o G1, em Fevereiro do respectivo ano foram decretadas 1.934 medidas protetivas em favorecimento da mulher, em março esse numero aumentou para 2.500 percebe-se um crescimento nas solicitações de medida protetiva cujo objetivo é garantir a proteção das vitimas. Constatou-se nesse período o aumento de prisão em flagrante em fevereiro foram registradas 177 prisões e em março 268 (G1, 2020).

Em 2019 dos 3.739 casos de homicídios no Brasil $35 \%$ por cento foi designado para o feminicídios isso significa que a cada sete horas uma mulher se torna vitima de feminicídios pelo simples fato de ser mulher ao verificar o vinculo afetivo entre vitima e agressor revelase que $88,8 \%$ era companheiro ou ex-companheiros por esse motivo as mulheres que ficam em casa devido ao isolamento social estão expostas ao perigo (VIEIRA, 2020).

Por esse motivo, especialistas destacam a importância dessas mulheres buscarem por ajuda. Para isso foi desenvolvida algumas ferramentas que colaboram para prevenção dessas mulheres foi lançada uma plataforma digital que oferta canais de atendimento a essas vitimas entre eles estão o APP dos Direitos Humanos BR trata-se de um aplicativo em que a vitima realiza um cadastro e consegue realizar denuncias, esse aplicativo não visa somente denuncias de mulheres mas, qualquer tipo de violência que infrinja os direitos humanos contra criança, idoso e deficientes. Junto com a descrição dos casos podem ser enviados fotos e vídeos que comprovem tais atos sendo assim, esse App oferece socorro imediato as vitimas e mostra seguro na medida em que essas pessoas possam realizar essas denuncias dentro de suas próprias residências em locais dos quais sintam-se seguras. Ha também o site ouvidoria.mdh.gov.br, através desses canais a vitima, familiar ou vizinhos podem enviar vídeos ou fotos que possa ser comprovada situações de violência. A Magazine Luiza uma empresa de eletrodomésticos também desenvolveu um Aplicativo que ajuda essas vitimas a denunciarem seus agressores, por meio de um botão de denuncia as vitimas podem fingir que estão realizando alguma compra e com isso realizar a denuncia contra seu parceiro, segundo a presidente do conselho da respectiva empresa em Maio de 2020 houve um aumento de denuncias que chegou atingir quase $400 \%$ comparado a maio de 2019. Há também o programa "você não esta sozinha" esse APP permite que as vítimas salvem o contato de um assistente virtual que fica entre seus contatos e simula conversas como se fosse um de seus contatos através dessa medida as mulheres recebem suporte e orientações de forma sigilosa (GANDRA, 2020).

\section{CONCLUSÃO}

Conclui-se que a violência contra mulher é um tema pertinente que necessita cada vez mais de atenção 
tanto da sociedade como das autoridades competentes, o que se espera é que esses APP que foram desenvolvidos nesse período de pandemia possam se manter ativos por muito tempo para que assim essas mulheres tenham cada vez mais acesso aos canais de comunicação. Espera-se também que possam ser criados mais programas de acolhimento a essas vitimas.

Por fim espera-se que as informações contidas nesse estudo possam contribuir para a sensibilização da sociedade, acadêmicos e profissionais de saúde assim como as demais áreas que são envolvidas com a questão da violência contra mulher. Então se percebe a necessidade que se tem em abordar essa temática com mais compromisso tanto politico como de promoção à saúde dessas mulheres, e assim dar uma maior visibilidade a essa problemática.

\section{AGRADECIMENTOS}

Agradeço primeiramente a Deus, a minha família por todo apoio e incentivo. Por último e não menos importante aos meus professores que me instruíram a pensar criticamente e por compartilhar seus conhecimentos e experiências para que assim eu possa me tornam uma profissional competente e ética.

\section{REFERÊNCIAS}

ARJONA, Reciane Cristina. Violência doméstica contra mulher. Site JUS, 2020 Disponível em: $<$ https://jus.com.br/artigos/74965/violencia-domesticacontra-mulher >. Acesso em: 10 de Jul. 2020.

BORGES, Beatriz; LARA, Walace. Casos de violência contra mulher aumentam $30 \%$ durante a quarentena em SP. Site G1, 2020. Disponível em: <https://g1.globo.com/sp/saopaulo/noticia/2020/04/13/casos-de-violencia-contramulher-aumentam-30percent-durante-a-quarentena-emsp-diz-mp.ghtml>. Acesso em: 02 de Jul. 2020.

BRASIL. Lei Maria da Penha. Lei N. 11.340 de 07 de Agosto de 2006. Disponível em <http://www.planalto.gov.br/ccivil_03/_ato2004-

2006/2006/lei/l11340.htm>. Acesso em: 03 de Jul. 2020.

BERNADES, João Marcos; CASTANHEIRA, Elen Rose Lodeiro. Violência contra a mulher: o que acontece quando a Delegacia de Defesa da Mulher está fechada? Ciência \& Saúde Coletiva, v. 25, p. 483-494, 2020. Disponível em: <https://scielosp.org/article/csc/2020.v25n2/483-494/\#>. Acesso em: 23 de Jul. 2020.

FERREIRA, Matheus. Magalu ganha destaque na luta contra violência doméstica nas redes sociais. Geek Publicitário, 2020. Disponível em: <https://geekpublicitario.com.br/47746/magalu- violencia-

domestica/\#: :text=Para\%20acessar\%20o\%20bot\%C3\% A3o\%20de,a\%20quest\%C3\%A3o\%20da\%20viol\%C3\% AAncia\%20feminina>. Acesso em: 03 de Jul. 2020.

GANDRA, Alana. Ferramenta eletrônica ajuda mulheres vítimas de violência na pandemia. Site Agência Brasil. Rio de Janeiro, 2020.2 Disponível em: <https://agenciabrasil.ebc.com.br/geral/noticia/202004/ferramenta-eletronica-ajuda-mulheres-vitimas-deviolencia-na-pandemia>. Acesso em: 09 de Mai. 2020.

MACHADO, Dinair Ferreira et al. Violência contra a mulher: o que acontece quando a Delegacia de Defesa da Mulher está fechada?. Ciência \& Saúde Coletiva, v. 25, p. 483-494, 2020.

MAZZI, Carolina. Violência doméstica dispara na quarentena: como reconhecer, proteger e denunciar. Site O Globo, 2020. Disponível em: <https://oglobo.globo.com/sociedade/coronavirusservico/violencia-domestica-dispara-na-quarentenacomo-reconhecer-proteger-denunciar-24405355>. Acesso em: 30 de Mai. 2020.

VIEIRA, Pamela Rocha; GARCIA, Leila Posenato; MACIEL, Ethel Leonor Noia. Isolamento social e o aumento da violência doméstica: o que isso nos revela? Revista Brasileira de Epidemiologia. Rio de Janeiro, v. 23, abr. 2020. Disponível em: 


$$
\text { interite } 2 \text { evista }
$$

$<$ https://www.scielo.br/scielo.php?script=sci_arttext\&pid

2020

=S1415-790X2020000100201>. Acesso em 08 de Mai. 